\title{
Shared Responsibility between the Patient and the Orthopeds in Determining the Right Diagnosis and the most Appropriate Individual Well Timing Perfect Treatment
}

\author{
Antonín Cuc* \\ Department of Artifitial Intelligence, Czech Republic \\ *Corresponding author: Antonín Cuc, Department of Artifitial Intelligence, Prague, Czech Republic \\ Submission: 非 March 30, 2017; Published: 眥June 19, 2018
}

\section{Case Report}

Sometimes the doctors are nervous when a patient is comming who is not a professional physician-but despite he knows exactly his diagnosis, personal and family history, history of last recommended treatments in encyklopedic orthopadic literature and he has preliminary studied the most common actual recommended treatments and he knows both his own private and family anamneses, also he knows the multilateral contextual medical encyklopedic literature of Rehabilitations, Medicaments support, light orthopadic surgeries, total surgeries, CT imaging, Ultrasound paging, MRI and the most frequent risks of medical errors in Orthopady branche and about ten of the biggest fatal patient's risks in Orthopady, Radiologic Orthopady, Clinic Planning in Orthopady, etc. [1,2].

Experienced clever patient would rather not admit to his Doctor because the average proud Orthopad would probably hates his Patient preliminary just before the opening of his patient mouth. The Patient medical knowledge mostly could be next communication problems, not Patient support when you are

depend on yours Doctor's next dealing and common acceptable Dialog!

"The Patient informed agreements with medical planned working".

Those are only usual judicial manoevere inforced dependend Facts, as BIANCO for advantage for your Doctors and Providers Health care they have no legal for technical guarancy and personal or financial, organisational responsibilites to like hood Patients with probable frequently next medical illegal mistakes and yours casual Health Patient problems despite maybe there are some content with technical illegal medical mistakes in medical standard legal working. Your Patient life in CZ, it is namely worthless for example despite formal existence your formal Patient Constitutional Human Rights CZ to live, to accept legal Health care only, to justified Court processing trials with justified validated Criminal evidences only to regards Czech Laws Ordering, including technical requirements of harmonised laws EU/CZ for safety usage Medical Devices "CE".

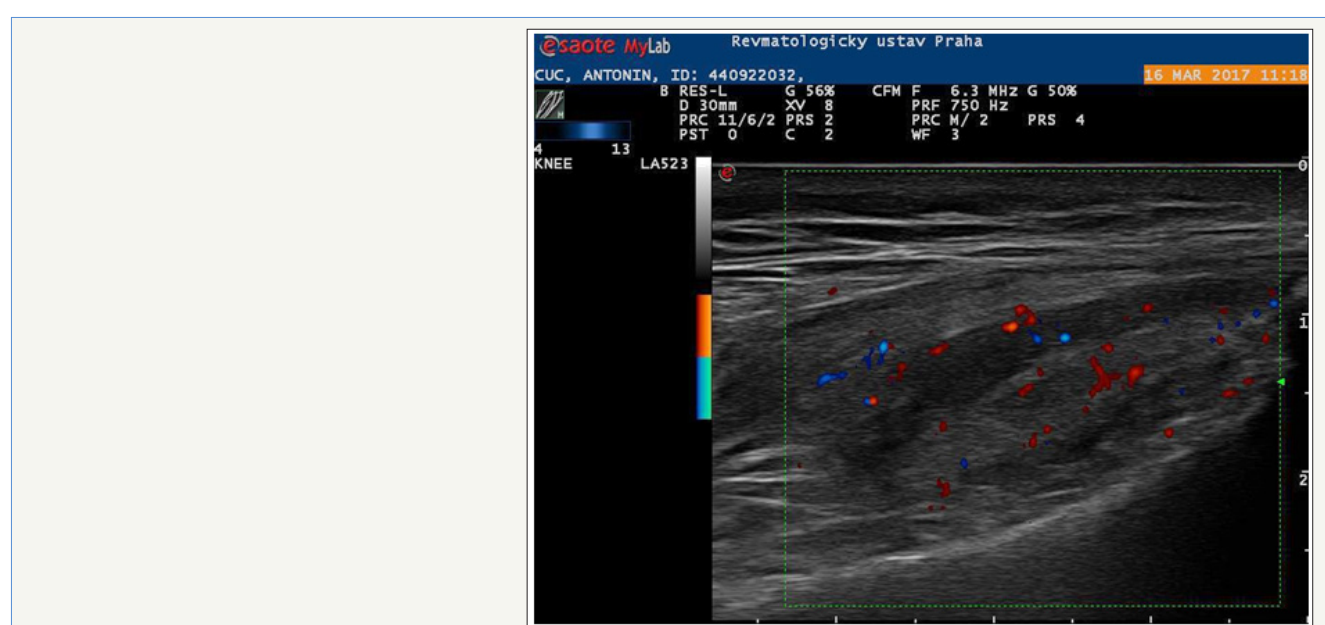

Figure 1: Revmatologic analyse of dysfunction left knee, Patient Antonin Cuc, Gonarthrosis. 
But I have spent many years as an expert on X-ray recognition in Geometry 3D with right interpretation Orthopadic technical repeated mistakes, and I am an expert in Cybernetics, orthopadic legal technical processing, safety partial measurement step by step and perfect timing partial activites in complicated medical processing, testing the legalitiy of Orthopadic clinic individual Planning, controlling legal archiving Patient Health documentation in databases EHRs, functional perfect testing the implanting Medical Implants after assembling-who proposes for the current level of Orthopedics the possibility of a much intensive larger share of artificial intelligence many of the daily orthopedic frequently working activities-and, on the other hand, I am the State Investigator in the field of patient mortality, experienced by criminal technical Anthropology analysis due to the illegal technical use of Medical Devices "CE" within the competence of the Ministry of Labor and Social Affairs of the Czech Republic. Maybe it is Ground for my secret wisdom as a crtical Patient CZ with finished my mortal injuries in ways "Health care in limits Lege Artis CZ" (Figure 1).

So I add that I'm just needless dying of many unnecessary and causally chained medical illegal technical orthopadic fatal mistakes in a usual standard processing orthopedic TEP hip surgery with a product "CE" set the Bicontact S noncemented, joint hip TEP the product Output by the firm B. Braun Germany. I have namely experienced the main surgery crash in Hall, as illegal installing dysfunctional implants "Fausse route of the shaft" when the Orthopad began working "blendy without mandatory Clinic individual Plan", but after that it was inforced me next complicated reoperation of the right artificial hip after 17 days, with many additional repeated risk surgeon cuttiíng and patient posto perational intensive pains and worse rehabilitation with duration many month my hospitalisation, the casual life-threatened nerve function of the ischidici without my mental control of the entire right snout forever.

I am just frequent happend in each year with constant dangerous growing the mortal risk to repeat breacking the femoral neck, despite it was possible to solve with Neuroplastics surgery of nervus ischiadici till 4 month after polytrauma "Fausse route stem". But my prime Orthopad-Traumatolog has no such sufficient medical knowledges, no similar as I have got as a Patient CZ-and then I shoud tolerate in next Knowing Medical Institute, the excess of being redundant X-ray orthopedic additional pictures with strong needless ionisation. That's for I'm just dying parallely for forced B-CLL Leukemia for me-never quite a previous fate tragedy in Ortopedia CZ! The Czech Criminal Police said with the Knowing Medical Institute surely against explicit duties from The Technical Requirements of harmonised Laws EU/CZ for usage Orthopadic Implants "CE". I tis illegal to placement set THA in biomechanic false illegal functionality implants "CE" in my Patient body (Figure 2):

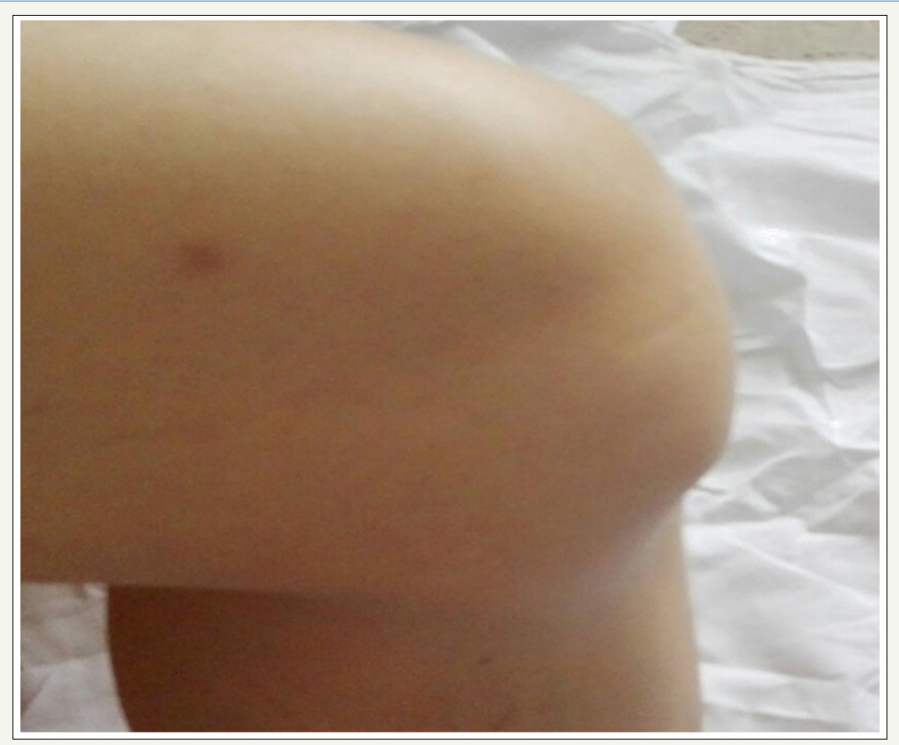

Figure 2: Heavy dysfunctional left knee, Gonarthrosis.

"All circumastances in all medical aspects there are officialy in usual limits Lege Artis CZ", but we are constant ignoring in Knowing Medical Insitute CZ, so as in Criminal Police CZ-all explicit Technical requirements of Laws, when you are a Patient CZ only it is worthless problem always your patient explanation principles - Biomechanics, Criminal traceing the spice of shaft, international fixed Regulations Health and Safety for Medical Devices "CE".....probable Patient has got accepted all contradictions - without next possibilities the Patient commentary in the Court dealing the judicial explanation Crash in surgery hall "Fausse route sten" itis official explained as substituted facts in Court Prtocols as "a postoperational virtual Patient happend fallen?"

Unbelieve! There are namely sometimes very idiotic vain Dialogs with many Orthopads CZ, Radiologists CZ, forensic Doctors CZ out of fields respects to principles scientic multilateral evidences Criominal traceing and including elementary principles Binary Logics with universal principles of construct balid results in conjunctions for partial sequential ordering phenomenons activites evaluated in mixed True, False in coherent scientic defined finished Results of sum in Math evaluating sequential structured legal 
Medical Processing. It must be always resulting as FALSE in case mixed phenomenons TRUE, FALSE! It never could be results defined and acceptable as justified judicial medical chnical understandable "Lege artis CZ"!

I hope just in better logical reliable Dialogs with US Orthopads and Readers in the US Research Orthopadic Journal about verified evaluating the legal OR illegal Medical standard processing in US Orthopady!

I would just like to describe a brief summary of my patient professional experiences with discussions with many physicians of CZ of many related medical disciplines in my new derived Health status-namely with my casual next inforced Diagnose additional Gonarthritis in my left Knee, The Gonarthrosis in the Population over Age 65+ Gonarthrosic knee is a very widespread polytraumatic orthopedic diagnosis, which means for most of the population older than 65 years of Age, with high medical moving problems and painful long-term multilateral care. In all OECD countries, $70 \%$ of the total population is affected by Gonarthrosy, it is amajor national economy for health and social and financial issues. In general, the consequences of gradual aging of the moving human apparatus-where the knee joint ranges are significantly reduced in dimensional functions, their real load capacity, gradual damage to the bones, tendons, worse efficient sliding surfaces of the joint mooving elements. Gradually, older people with experiences bone degradation, namely such as ostoeporosis, differences in right positions in axial functionall placement elements in joints in legs, revitalization of the knee tendons and muscles, reliable fixed of quality the muscles anchoring-it is very limited, because these tissues are mainly fed from articular fluids whose amount decreases internal structure the knee joint. Also the medication support by prescroptions of chondrosulfates is with a limited individual effect, blood circulations in weak physical activites of Patients are worse resulting for continual revitalisation your joints, your bones. In particular problems are frequently after sport injuries or uneven limbs, mostly individual Patient overweight for most part of older population, nutritional optimal structure composition of the individual food-all those influences are important aspects in the real functional ability of the knee joint stability, internal additional pains only the wear and functioning of the joints can be slightly affected.

What will be perfect individual processing Treatment in short time just for you? When you take the history of Sample with Dimensions about 600 Patients with Gonarthrosis, you could just recognise about 500 variants for individual medical processing and despite probable $85 \%$ of patiens over Age $65+$ with Gonarthrosis they are heavy more injured in duration degenerative locomotion abilities so as after comparison for duration 3 years individual incoherent Health care.

The Health Status will be probable always mostly worse and sometimes tragical colapsing of Patient moving with Loss of social self sufficiency in solitére housholders. We should take no personal private estimates of statistic multilateral parameters today's but we need used the objective independent representative multilateral random statistic analysis many aspects in experienced evaluating Orthopadic Research teams, namely of the random Clusters Patients Age 65+ including with competent usage computer dynamical moving standard tests, with next comparison efficient resulting parallel alternative treatments in sub-clusters similar as we just are used in high Sport managing for rehabilitation Health care by the best Athletes Olympionics or US Astronauts!

We should derived and creature the more clever defined standarding medical treatments in some important sub clusters Patients 65+, with Gonarthrosis in Knee today's situation is similar organisational principles, like in Brownian movement of Patients in net of Providers Health care with adequate growing the Assurance costs, but with weak Health and social effects, bad overloading today's Medical Capacities Ambulances, hospitals, rehabilitation and orthopadic Clinics.

I am recommending the use the orientation educative first Research Sample in dimension of 600 Patients in the Cohort, with usage the dependent database EHRs -and systematic statistic and medical decision making by the Method S - T -A -R -S-Statistical Retrieval and Search of information to Mass reuse for similar strategic decision making with risks and computer support by my Utility model 21532 CZ 2010

My Gonarthrosis in my left Knee, as a described here-as the random statistic entity-in the next Cluster Patients 65+ with Gonarthrosis Knee.

Typical pain firstly was manifested me inside my left knee, under the limb like squealing pain in duration my rehabilitation trip by bvcycling to a long mountain hill around June 2015 ion my Age 72. Within a few weeks, pain sometimes began to appear without a particular physical load, for example, vy changing of weather.

As an informed orthopedic patient, I began to systematically self-massages both my knees every day, but the main problem was in the constantly overloaded left knee-after the orthopedic full devastation of the nerve function of the sciatica in the right leg as casual following the "Fausse route of stem", in November 2007, when there are degradated muscles of right leg with weakness of the right leg forever. I should take the trekking sticks to prevency of my fatal dangerous happend Allen with repeated proximal breacking right femoral neck. In duration of year 2016, the systematic daily walking with treccking sticks, influenced my skeletal positions including my pelvis, with next degradation the left knee, postional of joint in the axe my left leg with casual more pains in left knee, frequently with big oedems and worse model of my walking. In the March 2017, I had to gain the medical advice from my Rehabilitation Doctor and he said: I am recommending the Magnetic field for rehabilitation, some self-massages, Lymfatic massages, light bicykling in Rotopads. He refused some invasive decompensation the oedem with injection suction for my worse Leukemia B-CLL with lack of hemoglobin 90 Units only in sample VolumeL and with overloading the blut structure with 300 thousands leukocyties. My Health status and locomotion abilities including oedem in the left knee were worse in 3 weeks. Thatsfor I was attending my Revmatolog 
he realised my intimate analyses of my internal left knee with processing Ultrasound Imaging with results: I am recommending you the puncture of your left Knee, but it will be better to realise in Orthopadic Surgeon hall carefully for your heavy Leukemia B-CLL. Then I attended my Clinic Orthopad and he said there are to late to puncture knee, but I am recommending you only Total Arthoplasty of left knee, despite todays your Patient standpoint is refused for your Leukemia B-CLL. Then I am attending my Regional Orthopad and he observed my left Knee with experimental Puncture of the Oedem but the content of oedem was just full heavy aspic, no chance to decompensation oedem with injection suction he prescribed me the individual orthopadic shoes.

I have got returned to my Hematolog on regularly Blood testing and he said you have just only 72 Units of hemoglobin in Serum, you should accept immediately infusion with big substituted Erytrocyties and we should continue with your Chemotherapy since
2 weeks you don't some medical advice about your limited moving abilities in your left knee maybe you are just probable dying.

Don't worry, be happy!

I am regret, my Patient wide knowledges about Orthopady, RTG imaging, locomotion rehabilitations, statistic decision making It could be probable for St. Peter in Heaven Gate without efficiency.

I hope in better results for next orthopadic Patients $65+$ with Gonarthrosis.

\section{References}

1. Antonín Cuc (2010) The equipment for statistical Search and Retrieval of information to Mass reuse for similar strategic decision making with risks and komputer support Utility model 21532, Czech Republic.

2. Pavel D, Coll (2005) Orthopady, Encyklopedia, Grada Publishing, (1 $1^{\text {st }}$ edn), Czech Republic.
Creative Commons Attribution 4.0

International License

For possible submissions Click Here

\section{Submit Article}

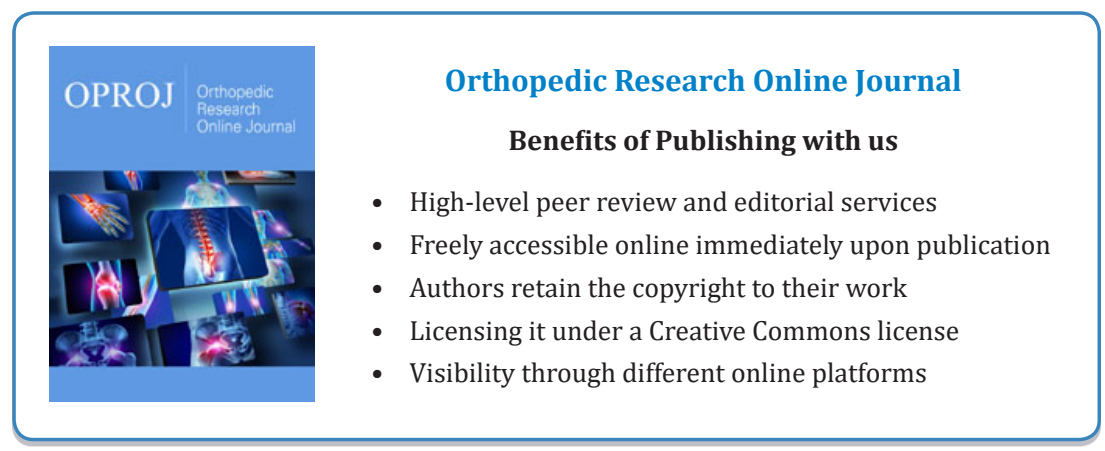

